\title{
Effects of COVID-19 pandemic control measures on air pollution in Lima metropolitan area, Peru in South America
}

\author{
Jhojan P. Rojas ${ }^{1}$ - Francesco R. Urdanivia ${ }^{1}$. Roy A. Garay ${ }^{1}$. Alan J. García ${ }^{1}$. Carlos Enciso ${ }^{1}$ - Elvis A. Medina ${ }^{1}$. \\ Richard A. Toro · Carlos Manzano ${ }^{2,3} \cdot$ Manuel A. Leiva-Guzmán² ${ }^{2}$
}

Received: 13 July 2020 / Accepted: 18 January 2021 / Published online: 4 February 2021

(c) The Author(s), under exclusive licence to Springer Nature B.V. part of Springer Nature 2021

\begin{abstract}
The sanitary measures implemented to control and prevent an increase in infections due to the COVID-19 pandemic have produced an improvement in the air quality of many urban areas around the world. We assessed air quality during the COVID-19 pandemic for particulate matter $\left(\mathrm{PM}_{2.5}\right.$ and $\left.\mathrm{PM}_{10}\right), \mathrm{NO}_{2}$ and $\mathrm{O}_{3}$ in in metropolitan area of Lima, Peru between pre-lockdown period (February 1 and March 15 of 2020), historical period (March 16 to April 30 2017-2019) and lockdown period (March 16 to April 30, 2020). The complete national lockdown that was implemented in Peru produced statistically significant reductions in the in-air pollutant $\left(\mathrm{PM}_{10}(-40 \%\right.$ and $-58 \%), \mathrm{PM}_{2.5}(-31 \%$ and $-43 \%)$ and $\mathrm{NO}_{2}(-46 \%$ and $\left.-48 \%)\right)$, as recorded by the by the ground-based air quality monitoring network throughout the metropolitan area, compared with the corresponding concentrations for the previous weeks and over the same period for 2017-2019. Analysis of the spatial Distribution of satellite data also show decreases in the concentrations of $\mathrm{PM}_{10}, \mathrm{PM}_{2.5}$ and $\mathrm{NO}_{2}$ as a result of the containment measures and suspension of activities implemented by the Peruvian government. The concentrations of $\mathrm{O}_{3}$ significantly increased (11\% and $170 \%)$ as a result of the decrease in the concentration of $\mathrm{NO}_{2}$, confirming that the study area is a hydrocarbon-limited system, as previously reported. The results obtained contribute to the assessment by the regulatory agencies of the possible strategies of control and monitoring of air pollution in the study area.
\end{abstract}

Keywords COVID- $19 \cdot$ Lockdown $\cdot$ Decline $\cdot$ Air pollution $\cdot$ Lima $\cdot$ Peru $\cdot$ Megacity

\section{Introduction}

The coronavirus disease of 2019 (COVID-19) is a viral infection generated by the severe acute respiratory syndrome coronavirus 2 (SARS-CoV-2). This disease manifests clinically as a severe acute respiratory syndrome with symptoms of fever, dry cough, dyspnea, respiratory disorders and pneumonia that can lead to progressive respiratory failure and death (Gorbalenya et al. 2020; WHO 2005; Zhou et al. 2020; Zhu et al. 2020). Human-to-human transmission of SARS-CoV-2 was confirmed in Wuhan (China) on

Manuel A. Leiva-Guzmán

manleiva@uchile.cl

Servicio Nacional de Meteorología E Hidrología, Lima, Peru

2 Department of Chemistry, Faculty of Science, University of Chile, Santiago, Chile

3 School of Public Health, San Diego State University, San Diego, CA, USA
January 20, 2020 (Kucharski et al. 2020). However, global mobilization of infected people in advance of the implementation of control measures (Jenson 2020; Kenyon 2020) resulted in numerous epidemic chains that produced new outbreaks in different nations. SARS-CoV-2 has inevitably spread throughout South America (WHO 2020). The first confirmed case in Latin America occurred in Brazil on February 26, 2020 (WHO 2020). In the following days, cases were reported in Mexico (February 28), Ecuador (February 29), Argentina (March 3), Chile (March 3) and Colombia (March 6). The first confirmed case in Peru occurred on March 6, 2020 (MINSA 2020).

Air pollution has decreased in cities around the world because of restrictions ("closures") imposed to limit the spread of SARS-CoV-2 (Coccia 2020; Kucharski et al. 2020; Muhammad et al. 2020; Saadat et al. 2020). Recently, researchers have reported that partial or complete lockdowns implemented in response to the pandemic have caused decreases in air pollutant concentrations in different cities and megacities in China (Bao and Zhang 2020; He et al. 
2020; Wang and Su 2020; Xu et al. 2020a, b), India (Mahato et al. 2020; Sharma et al. 2020), Malaysia (Abdullah et al. 2020), Brazil (Dantas et al. 2020; Nakada and Urban 2020), Australia (Sánchez-García and Leon 2020), Canada (CBC 2020), Italy (Collivignarelli et al. 2020), Spain (Tobías et al. 2020) and the United States (CNBC 2020). In several cities in China, measures to suppress the spread of COVID19 have led to a remarkable improvement in air quality. (He et al. 2020) reported that the $\mathrm{PM}_{2.5}$ (particulate material smaller than $2.5 \mu \mathrm{m}$ ) concentration decreased by $25 \%$ from that over the same period in 2019 and that this pollution reduction is beneficial to public health in the short term as long as the measures implemented by COVID-19 are maintained. Within a few days of forced restrictions, reduced pollution levels were observed in cities across India (Mahato et al. 2020). Also, reductions were observed on the order of $60 \%$ and $40 \%$ in the $\mathrm{PM}_{10}$ (particulate material with aerodynamic diameter smaller than $10 \mu \mathrm{m})$, e.g. Sale, Morocco (Otmani et al. 2020), New Delhi, India (Mahato et al. 2020), Milan, Italy (Collivignarelli et al. 2020), and $\mathrm{PM}_{2.5}$ levels, e.g. Milan, Italy (Collivignarelli et al. 2020), Zaragoza, Spain, Shanghai, China, New York, USA, Rome, Italy, Los Angeles, USA (Chauhan and Singh 2020). On the order reducctions of $53 \%$ and $30 \%$ for $\mathrm{NO}_{2}$ levels were observed, e.g. Milan, Italy (Collivignarelli et al. 2020), Sao Paulo, Brazil (Nakada and Urban 2020)) and CO levels, e.g. Milan, Italy (Collivignarelli et al. 2020), Rio de Janeiro, Brazil (Dantas et al. 2020), New Delhi, India (Mahato et al. 2020). The results of another study in India showed that reduced $\mathrm{PM}_{2.5}$ levels resulting from lockdown measures have counteracted increased pollutant concentrations from unfavorable weather conditions (Sharma et al. 2020). In Malaysian cities, reductions of between 30 and $60 \%$ in $\mathrm{PM}_{2.5}$ have been observed (Abdullah et al. 2020). In Sao Paulo, Brazil, drastic reductions in the concentrations of $\mathrm{NO}$ (nitrogen monoxide, up to $77 \%$ ), $\mathrm{NO}_{2}$ (up to $54 \%$ ) and CO (up to 65\%) have been observed in urban areas during partial lockdowns compared to the five-year monthly means (Nakada and Urban 2020). Also, in other studies, spaceborne $\mathrm{NO}_{2}$ column observations from two high-resolution instruments (TROPOMI and OMI), reveal unprecedented $\mathrm{NO}_{2}$ decreases over China, South Korea, western Europe, the United States (Bauwens et al. 2020) and Spain (Petetin et al. 2020) as a result of public health measures enforced to contain the coronavirus disease outbreak (Covid-19). These decreases observed have mainly resulted from reductions in urban road transport in many regions, with additional contributions from decreased industrial and commercial activity.

The highest infection rates have been reported in areas of high population density (Chauhan and Singh 2020). Over $30 \%$ of the population of Peru is concentrated in the Lima metropolitan area (LMA) (INEI 2020). The government of Peru implemented a complete national lockdown that drastically reduced anthropogenic activities (ED 2020). In this study, the impact of the sanitary measures implemented in the LMA to reduce the spread of the COVID-19 on the air quality are quantified by comparing the concentrations of particles $\left(\mathrm{PM}_{10}\right.$ and $\left.\mathrm{PM}_{2.5}\right)$ and $\mathrm{NO}_{2}$ during pre-lockdown period (February 1 and March 15 of 2020), historical period (March 16 to April 30 2017-2019) and lockdown period (March 16 to April 30, 2020). The results of this study can provide indicators of compliance with measures against COVID-19 and are therefore useful for both air pollution and public health regulatory agencies.

\section{Materials and methods}

\section{Study area}

The LMA is made up of the provinces of Lima (capital of the Republic of Peru) and Callao (Fig. 1), forming an extensive and populous urban area; it is one of the five megacities of South America, with a population of approximately 10 million inhabitants (population density of 3278.9 inhabitants/ $\mathrm{km}^{2}$ for Lima and 6815.8 inhabitants $/ \mathrm{km}^{2}$ for Callao). It is located in the central and western zone of the South American continent (longitude $77^{\circ} \mathrm{W}$ and latitude $12^{\circ} \mathrm{S}$ ) in a large alluvial plain formed by the valleys of the Chillón, Rímac and Lurín rivers (IGN 2014). The LMA climate is subtropical, with a mean annual temperature of $19{ }^{\circ} \mathrm{C}$ and a relative humidity of 80\% (SENAMHI 2016). The amount of rainfall barely reaches $10 \mathrm{~mm}$ per year, but cloudy skies are common throughout the year.

\section{Air pollution database and statistical analysis}

For each station, data from February, March and April from 2017 to 2020 were used to calculate the mean levels of each pollutant at different time scales. The period between 1 February 1 and March 15 of 2020 was considered the prelockdown period and that between March 16 and April 30 of 2020 was defined as the lockdown period. Likewise, the mean of the data from March 16 to April 30 in the years 2017, 2018 and 2019 was used for the historical period. Hourly mean concentrations were used in the analysis. The relative change (\%) in the concentrations was assessed by calculating and comparatively analyzing the concentration variations over the pre-lockdown, lockdown and historical periods. Before analysis, the data were validated to rectify duplicate entries and gaps.

The LMA has a real-time air quality monitoring network (AQMN) (SENAMHI 2020). The data from the monitoring network are the responsibility of the National Meteorological and Hydrological Service (Servicio Nacional de Meteorología e Hidrología_SENAMHI), an 


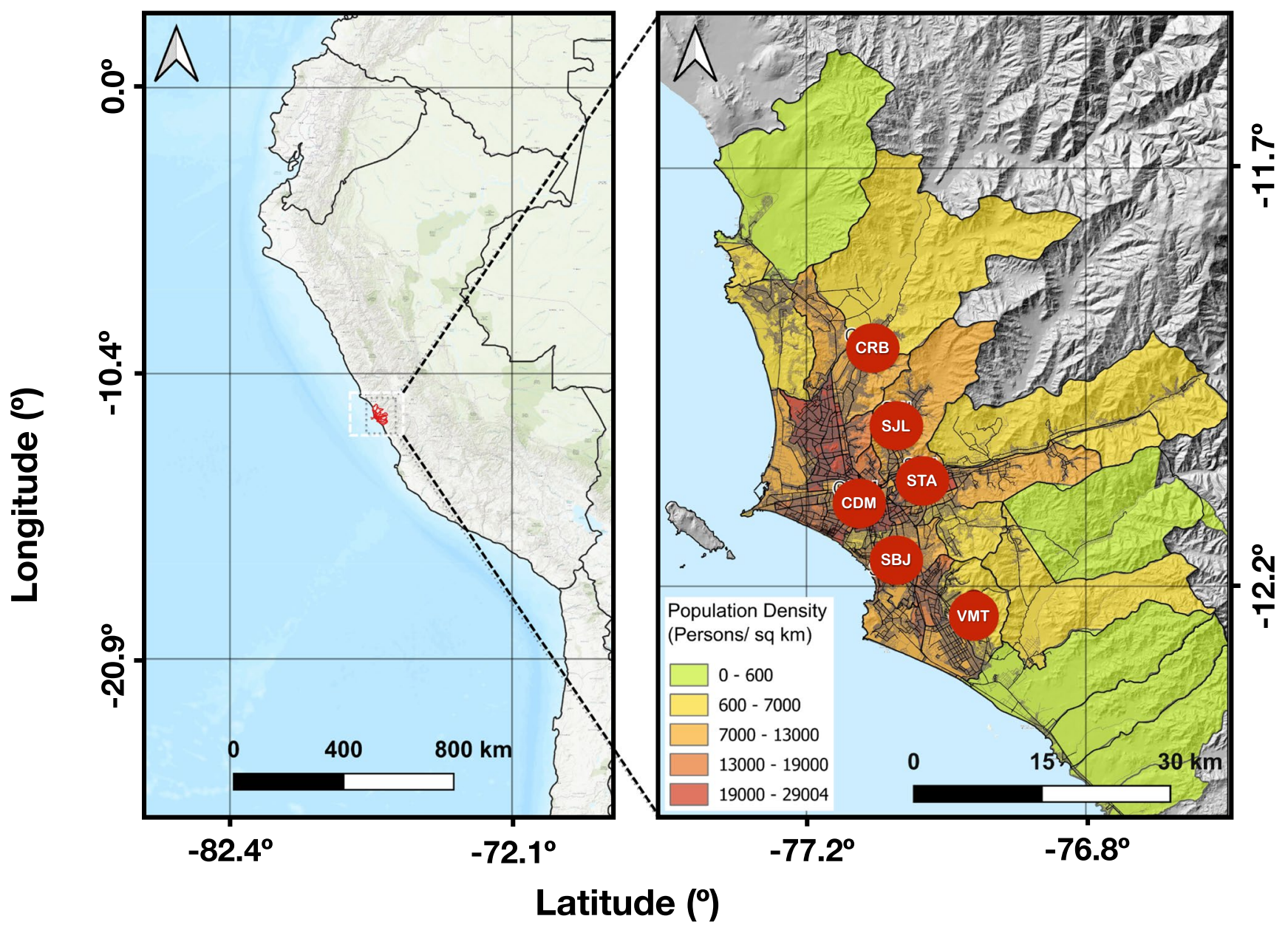

Fig. 1 Road map of LMA, population density and station locations of Lima air quality monitoring network; details on the network can be found in Table $\mathrm{S} 1$ of the supplementary material

entity attached to the Ministry of the Environment (Ministerio del Ambiente-MINAM). These stations measure atmospheric pollutant concentrations of $\mathrm{PM}_{10}, \mathrm{PM}_{2.5} \mathrm{NO}_{2}$ and $\mathrm{O}_{3}$ on an hourly basis. $\mathrm{PM}_{10}$ and $\mathrm{PM}_{2.5}$ are monitored at five of the six stations in the network under study while ozone and NO2 is only one stations (see Table $\mathrm{S} 1$ for more information related to station names, measurement principles and instrumentation in supplementary material). Meteorological variables (that is, the temperature, relative humidity, wind speed and direction) are also measured. The stations are located in urban environments that are mainly impacted by emissions from vehicular traffic and residential emissions (Silva et al. 2017, 2018).

\section{Spatial distribution analysis}

In addition to the temporal analysis, a spatial distribution analysis of $\mathrm{NO}_{2}$ levels was performed for in pre-lockdown and lockdown periods using satellite monitoring data. The data are obtained from remote sensing provided by the Copernicus Sentinel-5 Precursor Tropospheric Monitoring Instrument (S5p/TROPOMI), developed by the European Space Agency (ESA) (ESA 2018), at a spatial resolution of $0.01^{\circ} \times 0.01^{\circ}$ and daily temporal resolution. In both cases, the data were downloaded in NetCDF format and then processed in the software R (Team 2020) and/or Python (Python 2020). 


\section{Statistical analysis}

The descriptive statistical analysis was performed in MSExcel (Excel® 2017) and using the open source software programming language R (Team 2020) with the Openair package (Carslaw and Ropkins 2012, 2020). The analysis of variance (ANOVA) is a well-known statistical approach for analyzing differences between group means (for air pollutant concentrations and meteorological variables). Different time series during the lockdown and non-lockdown periods were compared using ANOVA to statistically test whether the means were the same across the groups.

\section{Results and Discussion}

After the first confirmed COVID-19 case, occurred in Peru on March 6, 2020 (see Fig. 2), the government, through the Ministry of Health (Ministerio de la Salud-MINSA), put into operation a National Preparedness and Response Plan for the Risk of Introduction of the Coronavirus to strengthen surveillance, containment and response systems (MINSA 2020). On March 11, a state of health emergency was decreed at the national level (see Fig. 2). From March 12 to 15 , the number of positive cases in Peru increased to a total of 71 cases and were concentrated in the LMA (MINSA 2020). On March 15, a state of emergency was decreed (ED 2020), making Peru the first country in South America to take strict measures to prevent an increase in positive cases (see Fig. 2). These measures included mandatory social isolation (via a national lockdown) and a complete lockdown of the border, starting on March 16. On March 18, a national curfew was enacted to tighten the mandatory social distancing measures because people were not conforming to the lockdown restrictions, and the use of private vehicles was prohibited from March 19. Despite all the sanitary measures implemented, the number of confirmed cases in Peru surpassed 100,000 on May 20 (MINSA 2020).

The impact of the measures implemented during the state of emergency was to freeze production activities, as reflected by electricity consumption (COES 2020). Figure 2 shows the mean daily electricity consumption in Peru: the application of isolation and immobilization measures is coincident with a clear decrease of approximately $40 \%$ in the energy demand. This decrease in production activity is not counteracted by overconsumption by people forced to stay at home. The decrease in the electricity demand reflects the freezing of production activities and attendant potential sources of air pollutant emissions.

By April 30, 2020, that is, six weeks after the declaration of the national state of emergency on March 16, 2020, LMA contamination, in terms of the $\mathrm{PM}_{10}, \mathrm{PM}_{2.5}$ and $\mathrm{NO}_{2}$ concentrations, had decreased (Fig. 3, Table 1). Likewise, compared with the historical period (the three previous years), similar behavior was observed. These observed changes are analyzed in the following sections.

A $40 \%$ decrease in the $\mathrm{PM}_{10}$ level between the pre-lockdown and lockdown periods was observed. A similar trend was observed for the $\mathrm{PM}_{2.5}$ level, in terms of the magnitude of the relative change. The ANOVA results revealed a statistically significant decrease in the $\mathrm{PM}_{10}$ and $\mathrm{PM}_{2.5}$ concentrations from the pre-lockdown to the lockdown: the p-value was smaller than the significance level of 0.01 at a $99 \%$ confidence level. The highest decrease for both $\mathrm{PM}_{10}$ and $\mathrm{PM}_{2.5}$ levels was observed at the STA station. The smallest relative changes were observed at the CDM stations, which are located in a commercial area with large malls, small businesses, restaurants, etc. and are therefore highly impacted by emissions from vehicle traffic. Sustained commercial activity produced a smaller decrease in $\mathrm{PM}$ concentrations because of the lockdown for the CDM area than other zones. These other zones are mainly residential areas with unpaved streets, for which the reduction

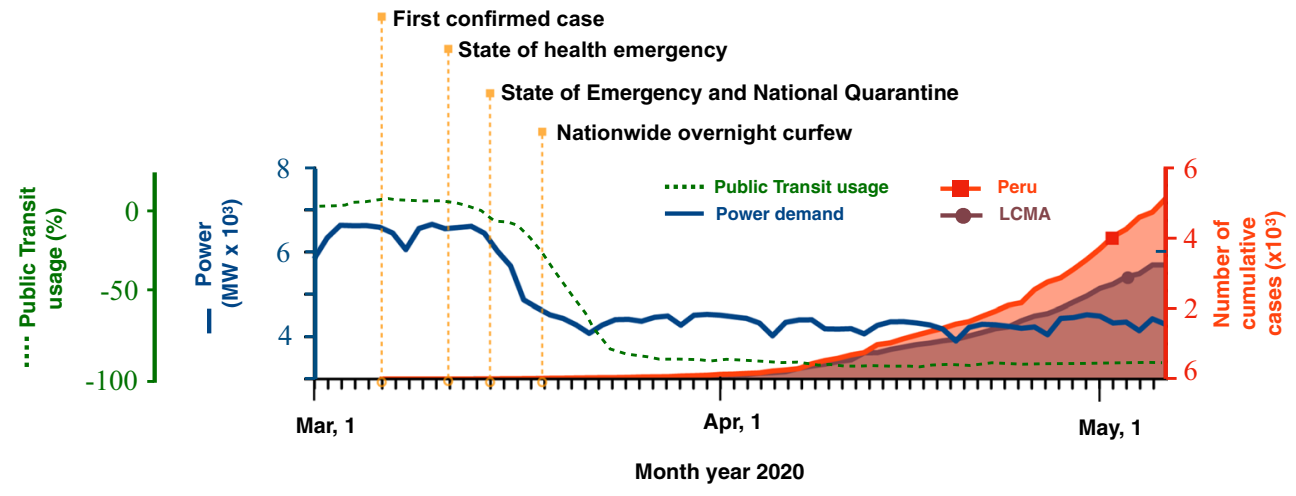

Fig. 2 Evolution of confirmed COVID-19 cases in Peru (red) and LMA (brown), national electricity demand (blue) and percentage of change in public transport use (green) 


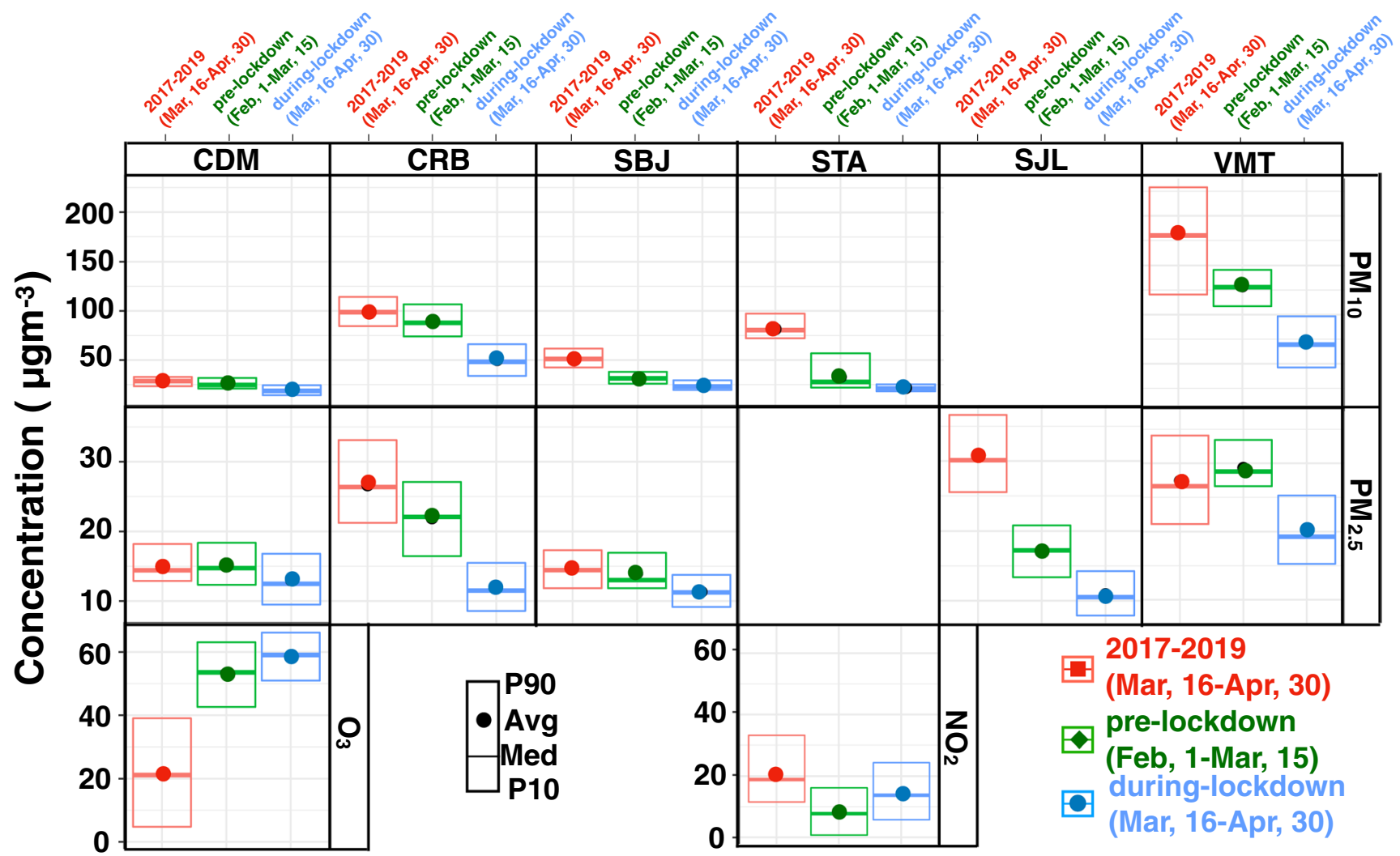

Fig. 3 Box plot (mean, median and 90th and 10th percentiles) by pollutant and station of LMA air quality monitoring network (see Fig. 1) mean, in red), B: Feb 1-Mar 15, 2020 (pre-lockdown, in green); C: for the following periods: A: Mar 16-Apr 30, 2017-19 (three-year

Table 1 Mean concentration in $\left(\mu \mathrm{gm}^{-3}\right)$ recorded by LMA air quality monitoring network for the following periods: A: Mar 16-Apr 30, 2017-19 (three-year mean); B: Feb 1-Mar 15, 2020 (pre-lockdown) and C: Mar 16-Apr 30, 2020 (during lockdown)

\begin{tabular}{|c|c|c|c|c|c|c|c|c|c|c|c|c|c|c|c|c|c|c|c|c|}
\hline \multirow[t]{2}{*}{ Station ID } & \multicolumn{4}{|c|}{$\begin{array}{l}\text { A: Mar 16-Apr 30, } \\
\text { 2017-19 (3-year mean) }\end{array}$} & \multicolumn{4}{|c|}{$\begin{array}{l}\text { B: Feb 1-Mar 15, } 2020 \\
\text { (pre-lockdown) }\end{array}$} & \multicolumn{4}{|c|}{$\begin{array}{l}\text { C: Mar 16-Apr 30, } 2020 \\
\text { (during lockdown) }\end{array}$} & \multicolumn{4}{|c|}{$\begin{array}{l}\text { C-A: Relative change } \\
([\mathrm{C}-\mathrm{A}] \times 1-00 / \mathrm{C}, \%)\end{array}$} & \multicolumn{4}{|c|}{$\begin{array}{l}\text { C-B: Relative change } \\
([\mathrm{C}-\mathrm{B}] \times 100 / \mathrm{C}, \%)\end{array}$} \\
\hline & $\mathrm{PM}_{10}$ & $\mathrm{PM}_{2.5}$ & $\mathrm{NO}_{2}$ & $\mathrm{O}_{3}$ & $\mathrm{PM}_{10}$ & $\mathrm{PM}_{2.5}$ & $\mathrm{NO}_{2}$ & $\mathrm{O}_{3}$ & $\mathrm{PM}_{10}$ & $\mathrm{PM}_{2.5}$ & $\mathrm{NO}_{2}$ & $\mathrm{O}_{3}$ & $\mathrm{PM}_{10}$ & $\mathrm{PM}_{2.5}$ & $\mathrm{NO}_{2}$ & $\mathrm{O}_{3}$ & $\mathrm{PM}_{10}$ & $\mathrm{PM}_{2.5}$ & $\mathrm{NO}_{2}$ & $\mathrm{O}_{3}$ \\
\hline CDM & 28 & 15 & - & 22 & 26 & 15 & - & 53 & 19 & 13 & - & 59 & -32 & -13 & - & 170 & -24 & -14 & - & 11 \\
\hline SBJ & 52 & 15 & - & - & 32 & 14 & - & - & 24 & 11 & - & - & -54 & -23 & - & - & -26 & -19 & - & - \\
\hline CRB & 98 & 27 & - & - & 90 & 22 & - & - & 50 & 12 & - & - & -49 & -55 & - & - & -44 & -45 & - & - \\
\hline SJL & - & 31 & - & - & - & 17 & - & - & - & 11 & - & - & - & -64 & - & - & - & -37 & - & - \\
\hline STA & 82 & - & 19 & - & 33 & - & 19 & - & 22 & - & 10 & - & -73 & - & -48 & - & -45 & - & -46 & - \\
\hline VMT & 182 & 27 & 21 & - & 129 & 29 & - & - & 71 & 20 & - & - & -61 & -26 & - & - & -34 & -31 & - & - \\
\hline AVG & 88 & 24 & 20 & 22 & 62 & 20 & 19 & 53 & 37 & 14 & 10 & 59 & -58 & -43 & -48 & 170 & -40 & -31 & -46 & 11 \\
\hline
\end{tabular}

in vehicular motion reduced vehicle emissions as well as particle resuspension. Thus, the lockdown produced a decrease in the PM concentration of approximately $50 \%$, which is similar in magnitude to the decrease in the NOx levels. This reduction can be explained in terms of the decrease in vehicular emissions by the lockdown measures, considering that the 2.2 million motor vehicles in the LMA make a total of nine million trips a day.
Ozone $\left(\mathrm{O}_{3}\right)$ is the only pollutant for which an increase in concentration (of 59\%) was observed during the lockdown period compared to the non-lockdown period, at the CDM station. This increase was shown to be statistically significant using ANOVA (the p-value was smaller than the significance level of 0.01 at a $99 \%$ confidence level). The increase in the $\mathrm{O}_{3}$ concentration can be explained in terms of the complex chemistry of $\mathrm{O}_{3}$ formation from mixtures of 
volatile organic compounds (VOCs) and NOx (FinlaysonPitts and Pitts 2000). A reduction in NOx concentrations leaves a higher number of $\mathrm{OH}$ radicals available to react with VOCs, promoting ozone formation. $\mathrm{O}_{3}$ is also eliminated via rapid reaction with NO. Thus, a reduction in available NO increases $\mathrm{O}_{3}$ atmospheric levels. This behavior is consistent with a previous report that $\mathrm{O}_{3}$ formation in the LMA is hydrocarbon-limited (Silva et al. 2018).

The variability in the $\mathrm{PM}_{10}, \mathrm{PM}_{2.5}, \mathrm{NO}_{2}$ and $\mathrm{O}_{3}$ concentrations over the historical period (March 16 to April 30) from 2017 and 2019 was similarly analyzed. The same general trends were observed as compared to the pre-lockdown period of 2020, albeit with more extreme concentration decreases. The highest decreases in the $\mathrm{PM}_{10}, \mathrm{PM}_{2.5}$ and $\mathrm{NO}_{2}$ concentrations were $73 \%, 64 \%$ and $48 \%$, respectively. A significant increase in variability was observed at the CDM station for $\mathrm{O}_{3}(166 \%)$ during the lockdown compared with the concentration for 2017-2019 and 2020. A comparison of the concentration values for the pairs of each pollutant and station for 2017-2019 and during the lockdown period in 2020 using ANOVA showed that the differences between these periods was significant (p-value $<0.01$ at a $99 \%$ confidence level).

No statistically significant differences were found between the temperatures, relative humidity and surface winds recorded during the pre-lockdown and lockdown periods in the present study. In general, in LMA the highest $\mathrm{PM}_{10}$ concentrations are observed in the summer and early autumn (February-April). On the other hand, regarding the $\mathrm{PM}_{2.5}$ concentrations, the highest concentrations are recorded between late autumn and winter (May and September). This could be explained by the subsidence thermal inversion weakens in the middle of spring and early fall and because the humidity decreases, which is detrimental to the formation of secondary particulate matter and contrary to what occurs during the cold and humid period (May-September) (Silva et al. 2017).

Figure 4 shows the spatial variability in the $\mathrm{NO}_{2}$ column $\left(\mu \mathrm{mol} / \mathrm{cm}^{2}\right)$ obtained from remote sensing provided by the Copernicus Sentinel-5 Precursor Tropospheric Monitoring Instrument (S5p/TROPOMI) for the pre-lockdown and
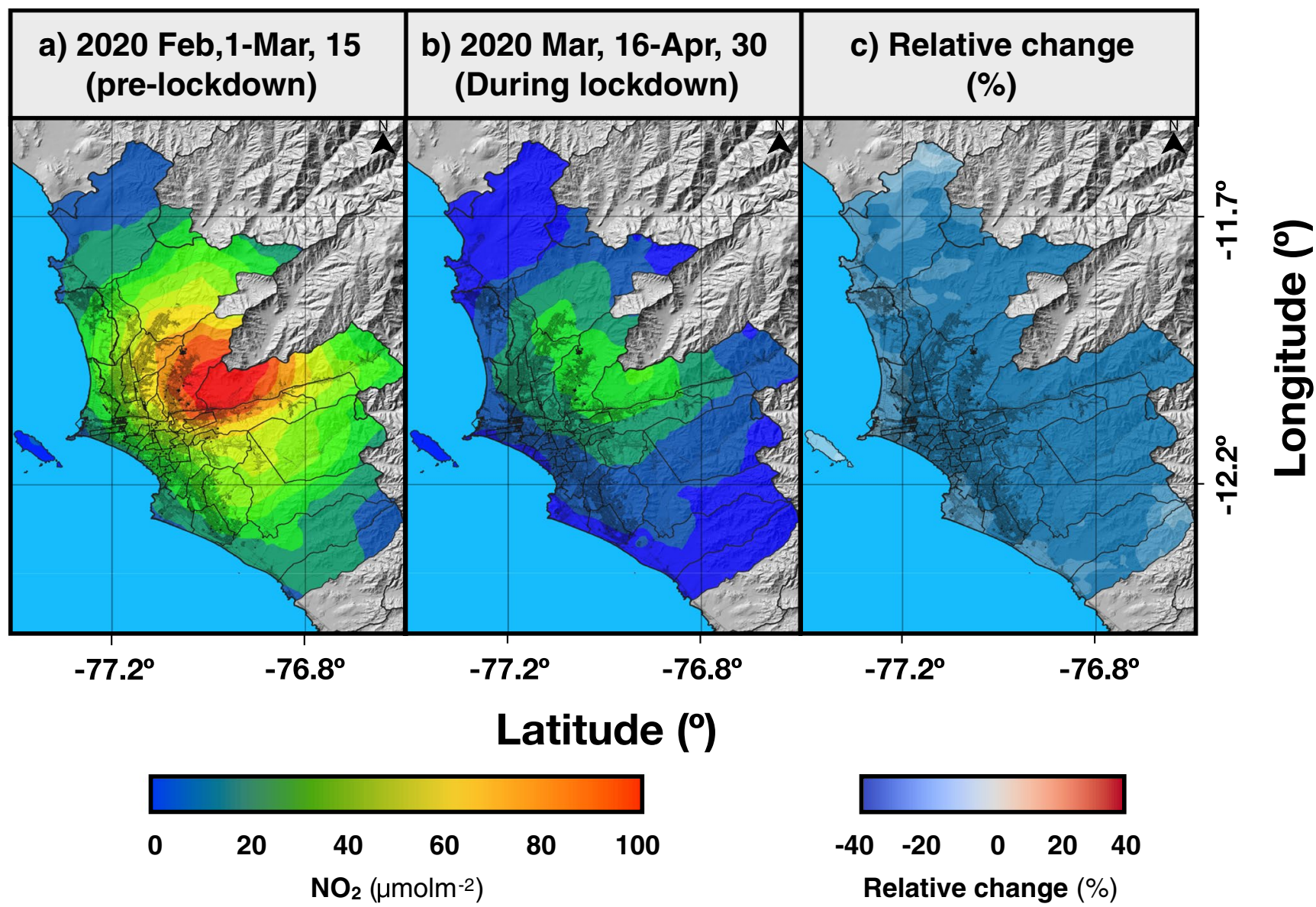

Fig. 4 Spatial distributions of LMA mean concentrations of $\mathrm{NO}_{2}$ (satellite data), during Feb 1-Mar 15, 2020 (pre-lockdown) and Mar 16-Apr 30, 2020 (during lockdown) and percentage relative change 
lockdown periods, as well as the corresponding relative change $(\%)$.

$\mathrm{NO}_{2}$ distribution in LMA is influenced by its proximity to the sea and winds, see Fig. 4a. In general, in the coastal area of the city, there are lower concentrations due to the coastal wind that blows from the ocean to the mountains (Silva et al. 2017). The main sources of outdoor air pollution are automotive fleet for these the reason the area of greatest impact turns out to be the downtown of the city where most vehicle traffic is focused and where important economic activity takes place (Romero et al. 2020; Silva et al. 2017). Likewise, the wind disperses the atmospheric pollution emitted in the downtown area towards the mountain slopes. Restrictive measures to prevent the spread of COVID-19 clearly reduce the sources of $\mathrm{NO}_{2}$ emissions in the city (see Fig. 4b).

The relative changes in the LMA NO${ }_{2}$ concentration are on the order of $-40 \%$ and are homogeneously distributed over the domain, which is consistent with the surface records from the STA station (see Table 1). Significant decreases in $\mathrm{NO}_{2}$ levels in the $40 \%$ to $30 \%$ range are evident over most of the urban area of the domain. The decreases in $\mathrm{NO}_{2}$ levels are on the same order of magnitude and exhibit the same trend as the surface records.

\section{Conclusions}

The LMA has experienced significant reductions in air pollution since a complete national lockdown was decreed during the COVID-19 pandemic. These results confirm the effects of the measures of social confinement and the suspension of productive activities on the concentrations of atmospheric pollutants observed in others in urban areas around the world. This article shows that a strong lockdown, such as that implemented in Peru, produces significant improvements in air quality. It is important to incorporate the effects of the local and synoptic meteorological factors that could influence the observed variations in this type of analysis.

These relative changes in air quality have also been shown to have positive impacts in reducing the possible impact of air pollution as a cofactor of morbidity and mortality for COVID-19 and other respiratory diseases (Anjum 2020; Pradhan et al. 2020). Although the lockdown has had demonstrably positive effects on the control and prevention of the spread of COVID-19 and the reduction in air pollution, there have been strong economic and social impacts in countries that have implemented restrictive measures. It is also important to mention that in part of South America, the winter period is beginning, with a reduction in temperature and a worsening of ventilation conditions and dispersion of pollutants, which are factors to consider in the management and assessment of the pandemic and its impact on the environment and vice versa. Other factors, such as weather conditions and the territorial distribution of infections, should be investigated in detail during the total lockdown implemented due to the pandemic to provide effective physical distancing with a lower socioeconomic impact.

Supplementary Information The online version contains supplementary material available at https://doi.org/10.1007/s11869-021-00990-3.

Author contributions Jhojan P. Rojas: Visualization; Methodology, Investigation; Francesco R. Urdanivia: Visualization, Data curation; Roy A. Garay: Data Curation; Alan J. Garcia: Data Curation; Carlos Ensiso: Data Curation; Elvis Medina: Data Curation; Richard Toro A.: Methodology, Investigation; Carlos Manzano: Review \& Editing; Manuel. A. Leiva-Guzmán: Conceptualization, Methodology, Funding Adquisition, Writing—Review \& Editing.

Funding We acknowledge the financial support of the Servicio Nacional de Meteorología e Hidrología del Perú (SENAMHI-Perú) for project SNIP N ${ }^{\circ} 199842$ "Extension and improvement of the monitoring network for the forecast of air quality in the metropolitan area of Lima" and program 096 (PPR096)-Management of air quality. One of the authors (MALG) acknowledges partial support from National Commission for Scientific and Technological Research CONICYT/ FONDECYT 2020 grant no. 1200674.

Data availability The data files are available at http://www.senam hi.gob.pe or by request to jprojas@ senamhi.gob.pe.

\section{Declarations}

Competing interest The authors declare that they have no known competing financial interests or personal relationships that could appear to influence the work reported in this paper.

\section{References}

Abdullah S, Mansor AA, Napi NNLM, Mansor WNW, Ahmed AN, Ismail M, Ramly ZTA (2020) Air quality status during 2020 Malaysia movement control order (MCO) due to 2019 novel coronavirus (2019-nCoV) pandemic. Sci Total Environ 729:139022. https://doi.org/10.1016/j.scitotenv.2020.139022

Anjum NA (2020) Good in The Worst: COVID-19 Restrictions and Ease in Global Air Pollution. https://doi.org/10.20944/PREPR INTS202004.0069.V1

Bao R, Zhang A (2020) Does lockdown reduce air pollution? Evidence from 44 cities in northern China. Sci Total Environ 139052. https ://doi.org/10.1016/j.scitotenv.2020.139052

Bauwens $\mathrm{M}$ et al (2020) Impact of Coronavirus Outbreak on NO2 Pollution Assessed Using TROPOMI and OMI Observations. Geophys Res Lett 47:e2020GL087978. https://doi.org/10.1029/2020G L087978

Carslaw D, Ropkins K (2020) OpenAir: Tools for the Analysis of Air Pollution Data, R package version 2.7.2, The Comprehensive $\mathrm{R}$ Archive Network (CRAN). Package openair - R Project, Availeble online: https://bit.ly/2SsoPXm. Accesed March 2020

Carslaw DC, Ropkins K (2012) openair - An R package for air quality data analysis. Environ Model Softw 27-28:52-61. https://doi. org/10.1016/j.envsoft.2011.09.008 
CBC (2020) Air pollution eases in 4 Canadian cities as pandemic measures keep people home, Canadian Broadcasting Corporation News. https://bit.ly/36dr2eU. Accessed May 2020

Chauhan A, Singh RP (2020) Decline in PM2.5 Concentrations over Major Cities Around the World Associated with COVID19. Environ Res:109634. https://doi.org/10.1016/j.envre s.2020.109634

CNBC (2020) Coronavirus: Air pollution plummets 30\% in Northeast US amid lockdowns, Consumer News and Business Channel. https ://cnb.cx/3cQks0G. Accessed May 2020

Coccia M (2020) Factors determining the diffusion of COVID-19 and suggested strategy to prevent future accelerated viral infectivity similar to COVID. Sci Total Environ 729:138474. https://doi. org/10.1016/j.scitotenv.2020.138474

COES (2020) COES SINAC (Economic Operation Committee of the National Interconnected System), Lima Peru. https://bit.ly/3cscn $1 \mathrm{~K}$. Accessed May 2020

Collivignarelli MC, Abbà A, Bertanza G, Pedrazzani R, Ricciardi P, Miino MC (2020) Lockdown for CoViD-2019 in Milan: What are the effects on air quality? Sci Total Environ:139280. https://doi. org/10.1016/j.scitotenv.2020.139280

Dantas G, Siciliano B, França BB, da Silva CM, Arbilla G (2020) The impact of COVID-19 partial lockdown on the air quality of the city of Rio de Janeiro, Brazil. Sci Total Environ 729:139085. https ://doi.org/10.1016/j.scitotenv.2020.139085

ED (2020) Emergency Decree No. 026-2020 Emergency decree establishing several exceptional and temporary measures to prevent the spread of the coronavirus (COVID-19) in the national territory. Presidency of the Republic of Peru, Lima, Peru. https://bit. ly/3dzqCCb. Accessed May 2020

ESA (2018) Copernicus Sentinel data processed by ESA, Koninklijk Nederlands Meteorologisch Instituut (KNMI), Sentinel-5P TROPOMI Tropospheric NO2 1-Orbit L2 7km x 3.5km, Greenbelt, MD, USA, Goddard Earth Sciences Data and Information Services Center (GES DISC). https://doi.org/10.5270/S5P-s4ljg54

Excel ${ }^{\circledR}$ M (2017) Microsoft Corporation ${ }^{\circledR}$, Redmond, Washington, USA Available oline: https://office.microsoft.com/excel. Accessed May 2020

Finlayson-Pitts BJ, Pitts JN (2000) CHAPTER 5 - kinetics and atmospheric chemistry. In: Finlayson-Pitts BJ, Pitts JN (eds) Chemistry of the upper and lower atmosphere. Academic Press, San Diego, pp 130-178. https://doi.org/10.1016/B978-012257060-5/50007-1

Gorbalenya AE et al (2020) The species Severe acute respiratory syndrome-related coronavirus: classifying 2019-nCoV and naming it SARS-CoV-2. Nat Microbiol 5:536-544. https://doi.org/10.1038/ s41564-020-0695-Z

He G, Pan Y, Tanaka T (2020) COVID-19, City Lockdowns, and Air Pollution: Evidence from China medRxiv:2020.2003.2029.20046649. https://doi.org/10.1101/2020.03.29.20046649

IGN (2014) National Geographic Institute, Republic of Peru [WWW Document]. http://www.ign.gob.pe (accessed 3.13.17).

INEI (2020) National Institute of Statistics and Information, Peru, Virtual Documentation System for Statistical Research - ANDA. https ://bit.ly/3e1psiZ. Accessed May 2020

Jenson HB (2020) How did "Flatten the Curve" become "Flatten the Economy?" A perspective from the United States of America. Asian J Psychiatry:102165. https://doi.org/10.1016/j. ajp.2020.102165

Kenyon C (2020) Flattening-the-curve associated with reduced COVID-19 case fatality rates- an ecological analysis of 65 countries. J Infect. https://doi.org/10.1016/j.jinf.2020.04.007

Kucharski AJ et al (2020) Early dynamics of transmission and control of COVID-19: a mathematical modelling study. Lancet Infect Dis 20:553-558. https://doi.org/10.1016/S1473-3099(20)30144-4
Mahato S, Pal S, Ghosh KG (2020) Effect of lockdown amid COVID19 pandemic on air quality of the megacity Delhi, India. Sci Total Environ:139086. https://doi.org/10.1016/j.scitotenv.2020.139086

MINSA (2020) Situation Room COVID-19 Peru. Ministry of Health, Republic of Peru. https://bit.ly/2yEfAwP, https://covid19.minsa .gob.pe/sala_situacional.asp. Accessed May 2020

Muhammad S, Long X, Salman M (2020) COVID-19 pandemic and environmental pollution: A blessing in disguise? Sci Total Environ 728:138820. https://doi.org/10.1016/j.scitotenv.2020.138820

Nakada LYK, Urban RC (2020) COVID-19 pandemic: Impacts on the air quality during the partial lockdown in São Paulo state, Brazil. Sci Total Environ:139087. https://doi.org/10.1016/j.scito tenv.2020.139087

Otmani A, Benchrif A, Tahri M, Bounakhla M, Chakir EM, El Bouch M, Krombi M (2020) Impact of Covid-19 lockdown on PM10, SO2 and NO2 concentrations in Salé City (Morocco). Sci Total Environ 735:139541. https://doi.org/10.1016/j.scito tenv.2020.139541

Petetin H, Bowdalo D, Soret A, Guevara M, Jorba O, Serradell K, Pérez García-Pando C (2020) Meteorology-normalized impact of the COVID-19 lockdown upon NO2 pollution in Spain. Atmos Chem Phys 20:11119-11141. https://doi.org/10.5194/acp-2011119-2020

Pradhan D, Biswasroy P, Kumar naik P, Ghosh G, Rath G (2020) A Review of Current Interventions for COVID-19 Prevention. Arch Med Res. https://doi.org/10.1016/j.arcmed.2020.04.020

Python (2020) Python Software Foundation. Python Language Reference, version 2.7. Available at http://www.python.org. Accessed May 2020

Romero Y, Chicchon N, Duarte F, Noel J, Ratti C, Nyhan M (2020) Quantifying and spatial disaggregation of air pollution emissions from ground transportation in a developing country context: Case study for the Lima Metropolitan Area in Peru. Sci Total Environ 698:134313. https://doi.org/10.1016/j.scitotenv.2019.134313

Saadat S, Rawtani D, Hussain CM (2020) Environmental perspective of COVID-19. Sci Total Environ 728:138870. https://doi. org/10.1016/j.scitotenv.2020.138870

Sánchez-García E, Leon J (2020) These 5 images show how air pollution changed over Australia's major cities before and after lockdown, The Conversation US. https://bit.ly/3bTzpOh. Accessed May 2020

SENAMHI (2016) Air quality assessment in Lima metropolitan area 2015 (in spanish). National Service of Meteorology and Hydrology of Peru (SENAMHI), Ministry of the Environment (MINAM), Republic of Peru. [WWW Document]. https://goo.gl/ $\mathrm{db} 2 \mathrm{JgU}$ (accessed 3.3.2020)

SENAMHI (2020) Air quality assessment in Lima metropolitan area . National Service of Meteorology and Hydrology of Peru (SENAMHI), Ministry of the Environment (MINAM), Republic of Peru. https://bit.ly/2zr6OST. Accessed May 2020

Sharma S, Zhang M, Anshika GJ, Zhang H, Kota SH (2020) Effect of restricted emissions during COVID-19 on air quality in India. Sci Total Environ 728:138878. https://doi.org/10.1016/j.scito tenv. 2020.138878

Silva J, Rojas J, Norabuena M, Molina C, Toro RA, Leiva-Guzman MA (2017) Particulate matter levels in a South American megacity: the metropolitan area of Lima-Callao. Peru Environ Monit Assess 189. https://doi.org/10.1007/s10661-017-6327-2

Silva JS, Rojas JP, Norabuena M, Seguel RJ (2018) Ozone and volatile organic compounds in the metropolitan area of Lima-Callao. Peru Air QualAtmos Health 11:993-1008. https://doi.org/10.1007/ s11869-018-0604-2

Team RC (2020) R: A language and environment for statistical computing. R Foundation for Statistical Computing, Vienna, Austria. Avaible online: http://www.R-project.org/. Accesed March 2020 
Tobías A et al (2020) Changes in air quality during the lockdown in Barcelona (Spain) one month into the SARS-CoV-2 epidemic. Sci Total Environ 726:138540. https://doi.org/10.1016/j.scito tenv.2020.138540

Wang Q, Su M (2020) A preliminary assessment of the impact of COVID-19 on environment - a case study of China. Sci Total Environ 728:138915. https://doi.org/10.1016/j.scito tenv.2020.138915

WHO (2005) Coronavirus disease (COVID-19) advice for the public, World Health Organization, Geneva, Switzerland. Available from: https://bit.ly/3g8Z34D. Accessed May 2020

WHO (2020) World Health Organization (WHO) Health Emergency Dashboard. Coronavirus Disease (COVID-19) Dashboard. Avaible online: https://covid19.who.int. Accessed May 2020

$\mathrm{Xu} \mathrm{H}$ et al (2020a) Possible environmental effects on the spread of COVID-19 in China. Sci Total Environ:139211. https://doi. org/10.1016/j.scitotenv.2020.139211
Xu K, Cui K, Young L-H, Hsieh Y-K, Wang Y-F, Zhang J, Wan S (2020b) Impact of the COVID-19 event on air quality in Central China. Aerosol Air Qual Res 20:915-929. https://doi.org/10.4209/ aaqr.2020.04.0150

Zhou P et al (2020) A pneumonia outbreak associated with a new coronavirus of probable bat origin. Nat 579:270-273. https://doi. org/10.1038/s41586-020-2012-7

Zhu N et al (2020) A Novel Coronavirus from Patients with Pneumonia in China, 2019 New England. N Engl J Med 382:727-733. https ://doi.org/10.1056/NEJMoa2001017

Publisher's note Springer Nature remains neutral with regard to jurisdictional claims in published maps and institutional affiliations. 